\title{
In the Pleasant World of Rats and Dampness
}

Do you have any kind of doors

install them and fix them in place

Not to hear Them

not to see Them.

Any kind of doors

as long as they are doors

Their closing system to be functioning well

but their opening system to be easy to break

by help of simple mechanism to close them

and not to open them any more.

Not to hear Them how They hear Themselves

not to see Them how They see Themselves.

With Their sounds

made of empty cans

In Their clothes

made of spotted cellophane.

Let us tie around our necks

washed ties

let us put on our pants from dry cleaners

Let us throw away the receipts which were given for service

when we carried away our watches

to be repaired

And let us close the doors with excellent mechanism

to prevent those who are with us

inside

from coming from outside.

Close the doors

and order one door more from the fat repairman

secure yourself with locks

and security devices 
when you will be asleep with a sweet dream

that They do not come to you to have tea and biscuits without rights.

Move yourself into the basement

live with the rats

and with dampness

in the pleasant world of rats and dampness.

Don't allow Them to knock at your doors

order doors without knocking

Invincible

thick doors

can help you

only those

Doors which are still being perfected

and are produced one by one

by very complicated tools in the open space.

Hammer in thick boards

on the slot made for the small letter that we expect to come

and make children's boats

of the paper

which you were keeping for the answers.

Make children's boats

and let them go through the drainpipes

let them be small submarines.

Live off doors

on their inner side

Bite them

eat

drink them

Lose your weight because of them

and gain your weight because of them

Cultivate them

warm yourself on them

and shiver close beside them.

Die

but do not revive memories

of an elevator

which brought you where you are 
of a travelling companion

and tomato juice.

Only sometime

so that you do not become mad

allow your friends to visit you

but let Them come in through other passageways

Those doors do not open.

Translated by the author and Branka Imamovic 